\title{
First report of watermelon mosaic virus isolated from Sicyos angulatus in Korea
}

\author{
Ji-Soo Park ${ }^{1}$ - Tae-Seon Park ${ }^{1}$ • Jin-Sung Hong ${ }^{1}$ (D) \\ Received: 26 August 2019 / Accepted: 3 December 2019 / Published online: 16 December 2019 \\ (C) Società Italiana di Patologia Vegetale (S.I.Pa.V.) 2019
}

Keywords Watermelon mosaic virus $\cdot$ Sicyos angulatus $\cdot$ Burcucumber

Sicyos angulatus, called Bur cucumber, is an annual plant in the gourd family, Cucurbitaceae, and a common plant on the roadside. In April 2016, we found Sicyos angulatus showing viruslike disease such as severe chlorosis and systemic mosaic symptoms on the roadway in Gapyeong, Gyeonggi-do, in Korea. Total RNA was extracted from the symptomatic leaves. We detected watermelon mosaic virus, named as WMV-Sa, from $S$. angulatus by RT-PCR using potyvirus degenerated primers (5'GTITGYGTIGAYGAYTTYAAYAA-3' [Nib(F)] and 5'TCIACIACIGTIGAIGGYTGNCC-3' [Nib(R)]) (Zheng et al. 2008). We tested the host response of Cucurbitaceae and tobacco plants by inoculating WMV-Sa to determine its host range. As the result, WMV-Sa induced systemic leaf curling and mosaic symptoms in Nicotiana benthamiana and chlorotic spots on upper leaves of Cucurbita pepo and Cucumis melo. However, WMV-Sa did not infect $N$. rustica, Chenopodium quinoa, C. amaranticolor, Cucumis sativus, and Citrullus vulgaris. To further characterize, we determined the full genome sequence of WMV-Sa (Genbank accession No. LC412927). WMV is a member of genus Potyvirus, and the length of genome is approximately $10 \mathrm{~kb}$. Therefore, we divided the WMV genome into 8 segments and amplified it by RT-PCR using specific primer sets. Each pair of primers is overlapped by $100 \sim 150 \mathrm{bp}$ and the size of amplified PCR products is about $1.3 \sim 1.5 \mathrm{~kb}$. Sequence alignment and phylogenetic analysis was carried out based on nucleotide and amino acid sequence of polyprotein of WMV-Sa and other isolates. These results showed that WMV-Sa isolates were closely related to the Yeongju6-1 isolate (KT992086), isolated from Panax ginseng in Korea, at 98.17\%/98.69\% (nt/aa) identity. To our knowledge, WMV-Sa infects only a few specific host plants ( $N$. benthamiana, C. pepo, and C. melo) and this is different from other WMV isolates reported previously. This is the first report of WMV infecting Sicyos angulatus in Korea.

Funding information This research was financially supported by Cooperative Research Program for Agricultural Science \& Technology Development (Project No. PJ014507032019).

\section{References}

Zheng L, Gibbs MJ, Rodoni BC (2008) Quantitative PCR measurements of the effects of introducing inosines into primers provides guidelines for improved degenerate primer design. J Virol Methods 153(2):97-103

Publisher's note Springer Nature remains neutral with regard to jurisdictional claims in published maps and institutional affiliations.
Jin-Sung Hong

jinsunghong@kangwon.ac.kr

1 Department of Bio-resources Sciences, College of Agriculture and Life Sciences, Kangwon National University, Chuncheon 24341, South Korea 